\title{
The Development of a Canadian Integrated Ocean Observing System (CIOOS)
}

\author{
Andrew Stewart ${ }^{1 *}$, Brad deYoung ${ }^{2}$, Mike Smit', Karen Donaldson', Alexa Reedman', \\ Andréane Bastien ${ }^{5}$, Ray Brunsting ${ }^{6}$, Bill Carter ${ }^{7}$, Brad Covey ${ }^{5}$, Richard Kelly ${ }^{7}$, \\ Eric Peterson ${ }^{6}$, Benoît Pirenne ${ }^{8}$, Ariane Plourde ${ }^{9}$, Anne-Sophie Ste-Marie ${ }^{5}$, \\ Cristina Tollefsen ${ }^{10}$, Douglas Wallace ${ }^{4}$ and Fred Whoriskey ${ }^{11}$
}

\begin{abstract}
${ }^{1}$ Fisheries and Oceans Canada, Ottawa, ON, Canada, ${ }^{2}$ Department of Physics and Physical Oceanography, Faculty of Science, Memorial University, St. John's, NL, Canada, ${ }^{3}$ School of Information Management, Faculty of Management, Dalhousie University, Halifax, NS, Canada, ${ }^{4}$ Marine Environmental Observation Prediction and Response Network, Halifax, NS, Canada, ${ }^{5}$ St. Lawrence Global Observatory, Rimouski, QC, Canada, ${ }^{6}$ Tula Foundation, Heriot Bay, BC, Canada, ${ }^{7}$ Fisheries and Marine Institute of Memorial, University of Newfoundland, St. John's, NL, Canada, ${ }^{8}$ Ocean Networks Canada, Victoria, BC, Canada, ${ }^{9}$ Institut des Sciences de la Mer de Rimouski (ISMER), Université du Québec à Rimouski, Rimouski, QC, Canada, ${ }^{10}$ Defence Research and Development Canada, Halifax, NS, Canada, ${ }^{11}$ Ocean Tracking Network, Dalhousie University, Halifax, NS, Canada
\end{abstract}

OPEN ACCESS

Edited by: Justin Manley,

Just Innovation, Inc., United States

Reviewed by: Christoph Waldmann, University of Bremen, Germany William Douglas Wilson, Independent Researcher, United States

*Correspondence:

Andrew Stewart Andrew.stewart@dfo-mpo.gc.ca

Specialty section: This article was submitted to Ocean Observation, a section of the journal Frontiers in Marine Science

Received: 07 November 2018

Accepted: 05 July 2019

Published: 09 August 2019

Citation:

Stewart A, deYoung B, Smit M, Donaldson K, Reedman A, Bastien A, Brunsting $R$, Carter $B$, Covey $B$, Kelly $R$, Peterson E, Pirenne $B$, Plourde A, Ste-Marie A-S, Tollefsen C, Wallace D and Whoriskey F (2019) The Development of a Canadian Integrated Ocean Observing System (CIOOS). Front. Mar. Sci. 6:431. doi: 10.3389/fmars.2019.00431
Ocean observation is fundamental to Canada's ocean science community. The federal government, academia, small businesses, not-for-profit organizations, and other research partners, collect and synthesize physical, chemical and biological observations for research purposes, to model ocean changes, to support resource management decision-making, and to establish baseline data for long-term monitoring. Aside from building comprehensive ocean observatories (Fisheries and Oceans Canada, 2010), there is no easy mechanism to integrate the large amounts of data from the various sources or to explore interrelationships among variables, and no coordination and collaboration mechanism for the ocean community as a whole to generate an efficient system Ocean Science and Technology Partnership (OSTP), for Fisheries and Oceans Canada (2011). Consequently, we observe fragmented and isolated data that is only discoverable by a limited range of end users. Canada's ocean science community (Wallace et al., 2014), led and supported by Fisheries and Oceans Canada (DFO), is developing a Canadian Integrated Ocean Observation System (CIOOS) that brings together and leverages existing Canadian and international ocean observation data into a federated data system. This system (Wilson et al., 2016) will improve coordination and collaboration among diverse data producers, improve access to information for decision making, and enable discovery and access to data to support a wide variety of applied and theoretical research efforts to better understand, monitor, and manage activities in Canada's oceans. Canada is implementing a ClOOS test-phase, which will eventually lead to the development of a robust and integrated observing system, improving connections between end users and providers of ocean observations. The improved coordination of regional and national efforts within ClOOS will contribute to global ocean observing, maximizing the overall benefit of integrated observing.

Keywords: ocean, observations, ocean observing systems, Canada, marine, data, data management, governance 


\section{INTRODUCTION}

The world's oceans are a critical component of the Earth system. Sound knowledge and understanding of the ocean is essential to mitigate human impacts on the global environment and to promote the ocean's sustainable use. Effective ocean management depends on observations of the ocean, which are generated by existing national or regional ocean observing systems and networks. Such data are also increasingly relevant to a broad array of stakeholders, with a recent report suggesting that the industry sector engaged with ocean observation had revenues of over $\$ 7$ billion in the United States alone, driven in part by their national ocean observing system (National Oceanic and Atmospheric Administration [NOAA], 2016).

Canada has the largest coastline of any nation in the world $(244,000 \mathrm{~km})$ along three ocean basins - Pacific, Arctic, and Atlantic. It has two major inland Seas, the Gulf of St. Lawrence, Hudson Bay, and the Laurentian Great Lakes. These waters are important to Canadians, serving as the backbone for the socio-economic well-being of Canada's coastal communities. The scale of our ocean resource poses many real challenges to developing a national observation system. The needs for ocean data vary significantly among regions, with conditions varying from extreme tidal dynamics in the Bay of Fundy, to the iceberg infested Grand Banks of Newfoundland, to the iced passages of the Arctic regions of Canada, and the coastal waters of the Salish Sea inside Vancouver Island. These regions support many different types of coastal communities with varying relationships with the ocean-from small fishing communities, to major ports, to First Nations, Métis, and Inuit communities distributed along the coasts up into the Arctic and Inuit Nunangat. Any nationally coordinated ocean observing system must, therefore, support ocean observing and share data to meet the needs of diverse groups of people countrywide, in addition to contributing to global efforts to address shared ocean issues.

Ocean science and observing in Canada are carried out by government, academia, non-governmental organizations, the private sector, and the general public (e.g., through citizen science). Many different sectors contribute, including coastal communities, Indigenous partners, fisheries, transportation, and tourism sectors. Canada's international memberships such as in the Intergovernmental Oceanographic Commission and the Arctic Council positions it well to contribute to global monitoring. Given the scale of the observational challenge, we must pay close attention to efficiency, necessary for longterm sustainability.

Fisheries and Oceans Canada (DFO) has the greatest investment and capacity for ocean science and serves as the lead agency for Canada’s cooperative international ocean observation efforts and has a mandate to pursue fundamental science to support and enhance fisheries and oceans management. Canada is an innovator in the development of specialized ocean observing capabilities. For example, ONC and Smart Ocean ${ }^{\mathrm{TM}}$ Systems offer continuous, near real-time monitoring and measurements throughout the year, and ONC has been a global leader in the design, operation and maintenance of cabled oceanographic systems (Heesemann et al., 2014). The SmartAtlantic Alliance supports operational efficiency, situational awareness, and safety in the marine environment, and the Ocean Tracking Network (OTN) is a global monitoring and internationally certified data system for tracking the movements of aquatic animals to provide the scientific foundation for sustainable oceans management (Hussey et al., 2015). SLGO promotes and facilitates access to and dissemination of data from the St. Lawrence ecosystem in support of public safety, climate change, transportation and resource management. The Ocean Frontier Institute is a transnational hub for ocean research, bringing together researchers from across the North Atlantic. Industry, Indigenous communities, NGOs, and the public also undertake ocean research, sometimes tied to the specific interests or values of their organization(s). There are good opportunities for private-public partnerships building first upon open and transparent data-sharing to address shared environmental concerns.

Until now Canada has lacked a national vision and strategy for coordinated ocean observation, resulting in overlaps and gaps in our observation activities, from collection to sharing and interpreting data. Canada needs an integrated ocean observing system to effectively and efficiently observe the ocean, and to gain the greatest value from its efforts.

Fisheries and Oceans Canada, in partnership with the Marine Environmental Observation Prediction and Response Network (MEOPAR), is spearheading the development of a Canadian Integrated Ocean Observation System (CIOOS) that brings together and leverages existing Canadian and international ocean observation data into a national data system. This national System (Wilson et al., 2016) will improve coordination and collaboration among data producers, ensure data and metadata interoperability, improve access to existing information, and enable discovery and reuse of data. These activities will support a wide variety of ocean science efforts to better understand, monitor, and manage activities in Canada's oceans leading to improved decision making. CIOOS will also provide a single access point for data of potential commercial or community value and serve as the foundation for the development of future ocean observation in the country. The formation of CIOOS is a step toward addressing the concerns highlighted by the Council of Canadian Academies [CCA] (2013), Expert Panel on Canadian Ocean Science 2013 report that identified poor coordination as a current fundamental weakness of Canadian marine science and the need for national governance structures to integrate existing regional efforts.

In moving to create its national ocean observing system, Canada benefits from the experiences and lessons learned by similar efforts in other countries. Many other countries recognize the need for national integration (e.g., O'Callaghan et al., 2019). Two models of particular interest are the U.S. Integrated Ocean Observing System (U.S. IOOS ${ }^{1}$ ) and Australia’s Integrated Marine Observing System (IMOS; Hill et al., 2010). Both systems were built by incorporating and scaling-up existing ocean observing capabilities. Such a process may be perceived as threatening for existing observation platforms or regional bodies. To garner community support, careful attention was paid during the

\footnotetext{
${ }^{1}$ https://ioos.noaa.gov/about/ioos-history/
} 
development of both systems to the governance structure that gives the community confidence that the new system would operate openly and transparently. National integration also enables communities to obtain significant new funding and recognition (e.g., the National Integrated Coastal and Ocean Observing Act of 2007 in the United States; the Australian Government's National Collaborative Research Infrastructure Strategy (NCRIS) support for IMOS) that flowed to the regions/platforms, an attractive carrot for those trying to sustain costly infrastructures. CIOOS governance is being crafted in a similar manner, and while the pathway to future funding is less clear at present, the existence of a valued national system will be instrumental in enabling new funding opportunities.

The United States and Australian experience also demonstrated the importance of inclusion. U.S. IOOS was initially focused on practical services to society (weather forecasts, flood control, advice to government), whereas IMOS was more academically focused. To prosper, both systems evolved to embrace the broadest possible array of stakeholders, meeting a wide variety of needs ${ }^{2}$ (Hill et al., 2010; Roughan et al., 2010; National Ocean Council, 2015). CIOOS from its start will engage with the broadest possible community. The importance of diversity, in all forms, is recognized in Canada. One important aspect of diversity, strongly supported, is partnership with Indigenous communities across the country. Their ties with the ocean span generations and they have rights, land claims, treaties, and governance structures over oceans and waterways, which ensure their role in ocean governance and management. Recognizing, respecting and including the values, expertise and traditional knowledge and Indigenous sciences of Indigenous peoples are essential to CIOOS.

\section{STRATEGY AND APPROACH TO THE DEVELOPMENT OF CIOOS}

The development of CIOOS has included several years of discussion, community meetings, white papers, and reports (Wallace et al., 2014; Smit et al., 2017; Tremblay et al., 2017; Whoriskey et al., 2017). This planning process for CIOOS has helped to unify the Canadian ocean observation community. The first step was to define key principles that help to unify the different actors who can contribute to the system, which should:

- Build on existing strengths;

- Include a wide variety of stakeholders, including Indigenous rightsholders;

- Have sustainability as a core feature;

- Support a culture of open data sharing;

- Be forward-looking and work to bring stakeholders and partners together; and

- Develop as an integrated system of regional nodes with many partners from different sectors.

Representatives from the federal government, academia, and non-governmental organizations worked together to develop

${ }^{2}$ https://ioos.noaa.gov/about/ioos-by-the-numbers/ the scope for a CIOOS. Based on recommendations derived from consultations with the ocean observing community, the pilot phase of CIOOS is underway and consists of three Regional Associations (RAs), a national web presence, and a data stewardship node. CIOOS will be led primarily by the RAs. In addition to DFO and MEOPAR, these RAs include universities (Memorial University and the Marine Institute, Dalhousie University, and the University of Victoria) plus existing networks such as SLGO, ONC, OTN, and the Hakai Institute, with the expectation that more partners will join in the future. The first steps will be to create user engagement plans, gather data from multiple providers within a data system, and demonstrate dissemination and visualization for an initial subset of Essential Ocean Variables (EOVs). CIOOS has been developed in line with the Global Ocean Observing System (GOOS) framework, in particular the use of EOVs as discussed in the Framework on Ocean Observing (Lindstrom et al., 2012) and with an eye to future inclusion of the currently developing Ecosystem and Biodiversity EOVs (Miloslavich et al., 2017; Muller-Karger et al., 2018).

A national web presence will provide core branding, an asset map and metadata catalog, and a data stewardship node will facilitate the development of data standards with partners. The core branding, a common look and feel across CIOOS, will be important to ensure partner organizations are recognized as an integral part of the community, and with the support of clear and consistent messaging, can demonstrate the benefits of CIOOS to new and future stakeholders (Mackenzie et al., 2019). The importance of branding and consistent messaging was one of the lessons learned from consultations with U.S. IOOS.

An effective national strategy and governance structure will help maximize the benefits of investments in the system, system capabilities, and national ocean science expertise through national coordination, leadership, and accountability (Fisheries and Oceans Canada, 2011). The multilevel governance model for CIOOS will allow for strong representation and mobility at the regional level, while ensuring a consistent national approach. An Executive Committee, with representatives from the regions and across stakeholder and rightsholder groups, ensures a clear and transparent decision-making process, integration across the whole of CIOOS, oversight for a common vision and implementation plan, and enables the sharing of best practices. At the regional level, a Board of Directors for each RA will gather feedback and ensure regional adaptability for their unique challenges and opportunities. Committees, with representatives from across the regions, will address more specialized issues and report to the Executive Committee (see Figure 1).

Already, there are strong networks of ocean observation in the Canadian Pacific, St. Lawrence, and Atlantic regions (Figure 2) monitoring a variety of ocean variables. The initial RAs to launch CIOOS are located in these areas. The System will grow to additional areas, e.g., the Arctic/Inuit Nunangat and the Great Lakes. Northern expansion is particularly important given the recent designation of an Arctic ocean region by DFO that is in partnership with and under the leadership of Inuit Nunangat.

The pilot phase focuses on the development of data infrastructure, including the data system architecture, the 


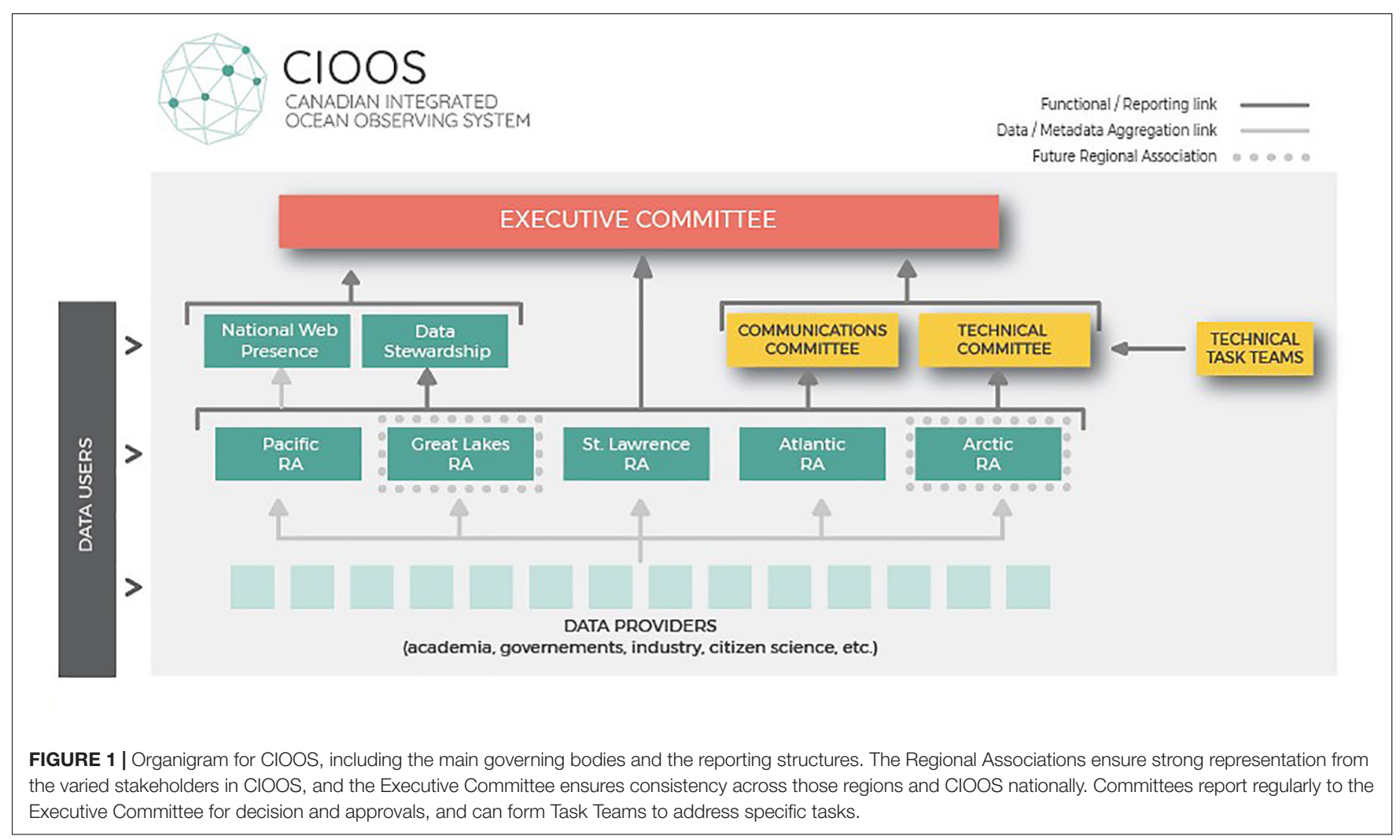

management structure and visualization tools, and begins by treating existing key data streams. By concentrating on a selection drawn from an initial subset of 11 EOVs, CIOOS will focus on development of a robust system that is scalable to new data types and variables, ensuring that the System is adaptable to new technology developments and societal changes. The initial 11 EOVs were agreed upon by the ocean observing community, based on quality and availability of data (Figure 2), and the ability of those variables to demonstrate the value of an integrated system by addressing national and international DFO mandates and ocean science community needs (Whoriskey et al., 2017).

The adoption of a common approach to metadata, software architecture, and data visualization is another critical piece of CIOOS. Within the ocean data management sector, there are a wide variety of competing standards, which were reviewed with recommendations during the design stage of CIOOS (Smit et al., 2017; Tremblay et al., 2017). It is important that good choices are made during the planning phases of the project. Due to the scope of work involved in making these decisions effectively, a technical decision-making structure is a part of the CIOOS project. A national Technical Committee, with representation from all regions oversees technical aspects of CIOOS, including metadata standards and practices, solution architecture and visualization tools. The Technical Committee initiates Task Teams to research and recommends to the Executive Committee on standards, frameworks, tools, methods and best practices. Task Teams include representation from all regions, in addition to external experts and collaborators. The Technical Committee helps to create and sustain collaborative working relationships between groups directly involved with developing CIOOS and national and international partners (Figure 1).

User engagement is critical to CIOOS, including training and capacity development. These activities will initially target a predominantly Canadian audience, focusing on the needs of regional data providers and users, as well as building awareness across the nation. The system will begin with a focus on meeting the needs of the initial partners, expanding to meet the wider needs of other groups as CIOOS matures. While CIOOS is currently focusing on a national approach, future phases of CIOOS could consider the basin-scale approach. Canada's coastlines are spread across three oceans, and so, in addition to Canadian partners, it will be important to work with international partners to develop basin strategies, such as the developing Atlantic Ocean Observing Blueprint (deYoung et al., 2019), and future initiatives such as an Arctic OOS.

\section{HOW CIOOS WILL BENEFIT CANADIANS}

Canadian Integrated Ocean Observation System will address immediate needs regarding quality and interoperability of ocean data, and will enable Canada to better adapt to changing requirements and a changing environment. Provision of open oceanographic data will help meet the societal needs for access to ocean information, benefit the country by assisting in the development of ground-breaking research, contribute to the global ocean observation efforts and provide 


\section{CORE VARIABLE READINESS BY REGION}

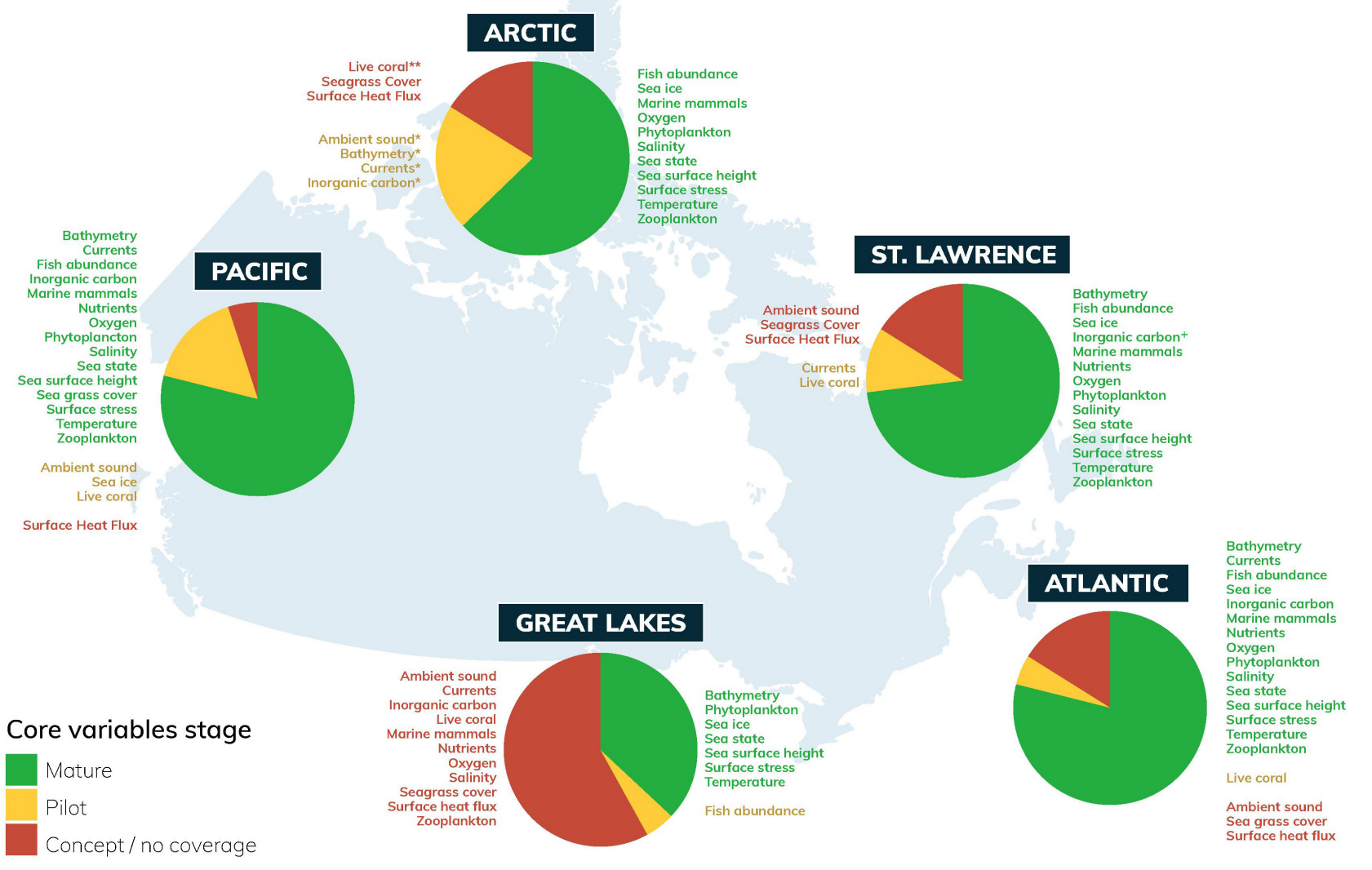

FIGURE 2 | Core variables readiness for GOOS compliance (level of maturity in terms of requirement process, coordination of observation elements, and data management and information product) according to GOOS three levels: Mature (green) -"products are well understood, documented, consistently available, and of societal benefit," Pilot (yellow) -"planning, negotiating, testing and approval within appropriate local, regional, global arenas," and Concept or have No Coverage (red) -"peer review of ideas and studies at science, engineering, and data management community level." * Mature technology, but low coverage. **Pilot, but low coverage. +Mature technology, but inconsistent sampling. Credit: St. Lawrence Global Observatory (SLGO) with data from Whoriskey et al. (2017).

opportunities for Canada to become a global leader in multidisciplinary ocean science.

The system's multi-level governance structure provides an opportunity to bring in new partners, both nationally and internationally, as emerging partners or observers. International involvement is important to ensure that as CIOOS grows, it enables Canada's engagement on the international ocean observing landscape (e.g., Barth et al., 2019), for example through the GOOS and the GOOS Regional Alliances (GRAs) and the proposed All Atlantic Ocean Observing System AtlantOS (deYoung et al., 2019). CIOOS will enhance ocean observing internationally, by ensuring the data are easily accessible, following the FAIR (Findable, Accessible, Interoperable, Reusable) principles of data management (Tanhua et al., 2019) and working with other countries to share innovations and value-added products. Many of the partner organizations contributing to the development of CIOOS are already involved in international projects. CIOOS can augment their international collaborations by providing new avenues and forums for partnerships.
CIOOS will help build ocean observing capacity across Canada, by reaching out to involve smaller organizations and communities, bringing together existing groups, and through enhanced collaboration and coordination strengthen existing activities. Many partners involved in CIOOS are world leaders in ocean observing and in the dissemination of ocean observing data, as noted above. The goal is for the national program to be stronger than the sum of all these components.

Ocean observing systems support many different human concerns about the ocean, from operational services, to ocean health, to climate. These concerns were behind the creation of GOOS. CIOOS will span these three key aspects of ocean observing by bringing together stakeholders from the ocean community to provide an integrated approach. Central to this approach is the partnership between the federal government and the academic community. This partnership will ensure that the strengths of each are mobilized to build the most flexible and dynamic system possible, and to ensure sustainable operations. This will require a focus on innovation to improve the efficiency and effectiveness of the System. The partnership also includes 
the private sector, to directly support the blue economy, the growth of which is rapidly accelerating, bringing both benefits but also challenges. CIOOS will regularly review the observing system activities to ensure that they are fit-for-purpose in the socio-economic sense to meet the needs of Canadians.

\section{LOOKING FORWARD}

Canada faces increasing demand for oceanographic data to support sustainable growth and address issues stemming from a changing ocean and needs a national data system to meet that demand. We currently face numerous environmental issues, including pollution, ocean acidification, sea-level rise, and managing sustainable fisheries. The challenges in addressing such issues include:

- Need for coordinated, global, sustained (long-term) data collection;

- Demand for timely access to data of known quality, information and knowledge, in user-friendly formats;

- Increasing data rates and volumes;

- Greater diversity of data types and observing instruments; and

- Limited collaboration mechanisms/structures to foster data standardization, integration, discovery, and visualization.

Only a national, integrated ocean observing system can address these challenges. We require a transparent process for decision making that will enable us to address key gaps in our observing activities. A system that encourages stakeholder engagement will help with system sustainability as it will be clearly seen to be meeting stakeholder needs which will encourage participatory support of the System. CIOOS will help to create

\section{REFERENCES}

Barth, J. A., Allen, S. E., Dever, E. P., Dewey, R. K., Evans, W., Feely, R. A., et al. (2019). Better regional ocean observing through cross-national cooperation: a case study from the Northeast Pacific. Front. Mar. Sci. 6:93. doi: 10.3389/fmars. 2019.00093

Council of Canadian Academies [CCA] (2013). Expert Panel on Canadian Ocean Science. Ocean Science in Canada: Meeting the Challenge, Seizing the Opportunity. Available at: http://scienceadvice.ca/reports/ocean-sciencein-canada-meeting-the-challenge-seizing-the-opportunity/ (accessed July 11, 2019).

deYoung, B., Visbeck, M., Araujo Filho, M. C., Baringer, M. O., Black, C.-A., Buch, E., et al. (2019). An integrated all-atlantic ocean observing system in 2030 . Front. Mar. Sci. 6:428. doi: 10.3389/fmars.2019.00428

Fisheries and Oceans Canada (2010). Ocean Science and Technology Partnership, With the Financial Support of the Canadian Space Agency. Canadian Survey of Atlantic, Pacific, Arctic and Great Lakes Observing Systems. Ottawa: Fisheries and Oceans Canada .

Fisheries and Oceans Canada (2011). Ocean Science and Technology Partnership. Lessons Learned from OOS in Canada: Preliminary Assessment of OOS Value. Available at: http://www.qc.dfo-mpo.gc.ca/publications/science/ documents/Preliminary\%20OOS\%20value\%20assessment_e.pdf (accessed July 11, 2019).

Heesemann, M., Insua, T. L., Scherwath, M., Juniper, S. K., and Moran, K. (2014). Ocean networks Canada: from geohazards research laboratories to smart Ocean Systems. Oceanography 27, 151-153. doi: 10.5670/oceanog.2014.50 the environment, and will encourage greater investment by the federal and provincial governments as well as by other partners who will contribute to and benefit from the observations.

Canadian Integrated Ocean Observation System will enable Canada to play a global leadership role in multidisciplinary ocean science and will provide access to valuable data currently not discoverable, especially within the extensive holdings of the federal government. This ocean observing system will help coordinate the collection of ocean data on a national scale, and critically, will be adaptable in the face of growing needs and a changing environment.

\section{VISION}

To develop an integrated ocean observation system that meets the needs of Canadians and contributes to global ocean observing.

\section{AUTHOR CONTRIBUTIONS}

All authors listed have made a substantial, direct and intellectual contribution to the work, and approved it for publication.

\section{ACKNOWLEDGMENTS}

We would like to thank the Canadian and the international ocean observing community for the support and input we have received and continue to receive in the development of CIOOS. We would also like to thank Fisheries and Oceans Canada and the Marine Environmental Observation, Prediction, and Response Network for funding this initiative.

Hill, K., Moltmann, T., Proctor, R., and Allen, S. (2010). The Australian integrated marine observing system: delivering data streams to address national and international research priorities. Mar. Technol. Soci. J. 44, 65-72. doi: 10.4031/ MTSJ.44.6.13

Hussey, N. E., Kessel, S. T., Aarestrup, K., Cooke, S. J., Cowley, P. D., Fisk, A. T., et al. (2015). Aquatic animal telemetry: a panoramic window into the underwater world. Science 348:1255642. doi: 10.1126/science.12 55642

Lindstrom, E., Gunn, J., Fischer, A., McCurdy, A., and Glover, L. K. (2012). A Framework for Ocean Observing. By the Task Team for an Integrated Framework for Sustained Ocean Observing, UNESCO 2012, IOC/INF-1284. Available at: http://unesdoc.unesco.org/images/0021/002112/211260e.pdf (accessed July 11, 2019).

National Oceanic and Atmospheric Administration [NOAA] (2016). The Ocean Enterprise: A study of US Business Activity in Ocean Measurement, Observation and Forecasting. Available at: http://www.ioos.noaa.gov/ioos_in_action/ocean_ enterprise_study.html (accessed July 11, 2019).

Mackenzie, B., Celliers, L., de Freitas Assad, L. P., Heymans, J. J., and Rome, N. (2019). The role of stakeholders and actors in creating societal value from coastal and ocean observations. Front. Mar. Sci. 6:137.

Miloslavich, P., Bax, N. J., Simmons, S. E., Klein, E., Appeltans, W., AburtoOropeza, O., et al. (2017). Essential ocean variables for global sustained observations of biodiversity and ecosystem changes. Glob. Change Biol. 24, 2416-2433. doi: 10.1111/gcb.14108

Muller-Karger, F. E., Miloslavich, P., Bax, N. J., Simmons, S., Costello, M. J., Sousa Pinto, I., et al. (2018). Advancing marine biological observations and 
data requirements of the complementary essential ocean variables (EOVs) and essential biodiversity variables (EBVs) frameworks. Front. Mar. Sci. 5:211. doi: $10.3389 /$ fmars.2018.00211

National Ocean Council (2015). US Integrated Ocean Observing System (U.S.IOOS ${ }^{\circledR}$ ) 2015 Report to Congress. Available at: https://cdn.ioos.noaa.gov/ media/2017/12/ioos_report_congress2015.pdf (accessed July 11, 2019).

O'Callaghan, J., Stevens, C., Roughan, M., Cornelisen, C., Sutton, P., Garrett, S., et al. (2019). Developing an integrated ocean observing system for New Zealand. Front. Mar. Sci. 6:143. doi: 10.3389/fmars.2019.00143

Roughan, M., Morris, B. D., and Suthers, I. M. (2010). NSW-IMOS: an integrated marine observing system for Southeastern Australia. IOP Conf. Ser. Earth Environ. Sci. 11:012030. doi: 10.1088/1755-1315/11/1/012030

Smit, M., Kelly, R., Fitzsimmons, S., Bruce, S., Bulger, C., Covey, B., et al. (2017). Canadian Integrated Ocean Observing System: Cyberinfrastructure Investigative Evaluation. Halifax, NS: Dalhousie University.

Tanhua, T., Pouliquen, S., Hausman, J., O’brien, K., Bricher, P., Bruin, T. D., et al. (2019). Ocean FAIR data services. Front. Mar. Sci. (in press). doi: 10.3389/fmars. 2019.00440

Tremblay, C., Desjardins, A. B., Dewey, R., Guillemot, E., Lapointe, S., Owens, D., et al. (2017). Canadian Integrated Ocean Observing System: Visualization Investigative Evaluation. Available at: https://ogsl.ca/commons/doc/cioos_ie_ vis.pdf

Wallace, D. R., de Young, B., Iverson, S., Laroche, J., Whoriskey, F., Archambault, P., et al. (2014). "A Canadian contribution to an integrated atlantic ocean observing system (IAOOS)," in Proceedings of the Presented at the IEEE/OES Marine Technology Society OCEANS 2014, (St. John's, NL: IEEE).

Whoriskey, F. G., Morton, K., Bajona, L., Beck, M., Dewey, R., Guillemot, E., et al. (2017). Tremblay. Canadian Integrated Ocean Observing System Investigative Evaluations: Observation and Data. Available at: http://meopar.ca/uploads/IE_Report_-_Observations_and_Data.pdf (accessed July 11, 2019).

Wilson, L., Smit, M., and Wallace, D. W. R. (2016). "Towards a unified vision for ocean data management in canada: results of an expert forum)," in Proceedings of the Advancing the Frontiers of Data in Research from SciDataCon 2016, Denver, CO.

Conflict of Interest Statement: The authors declare that the research was conducted in the absence of any commercial or financial relationships that could be construed as a potential conflict of interest.

Copyright $(2019$ Stewart, deYoung, Smit, Donaldson, Reedman, Bastien, Brunsting, Carter, Covey, Kelly, Peterson, Pirenne, Plourde, Ste-Marie, Tollefsen, Wallace and Whoriskey. This is an open-access article distributed under the terms of the Creative Commons Attribution License (CC BY). The use, distribution or reproduction in other forums is permitted, provided the original author(s) and the copyright owner(s) are credited and that the original publication in this journal is cited, in accordance with accepted academic practice. No use, distribution or reproduction is permitted which does not comply with these terms. 